\title{
Inspiratory Plus Expiratory Neuromuscular Electrical Stimulation Versus Diaphragm Pacing for Rehabilitation in Severe COPD Patients: A Randomized Controlled Trial
}

\section{Zhiling Zhao}

Department of Respiratory and Critical Care Medicine, Beijing Chaoyang Hospital, Capital Medical University, Beijing, China. https://orcid.org/0000-0002-5074-1777

\section{Xiaojuan Wang}

Department of general medicine, Beijing Chaoyang Hospital, Capital Medical University, Beijing, China.

\section{Wuzhuang Sun}

Department of Respiratory Medicine and PCCM, The First Hospital of Hebei Medical University, 89 Donggang Road, Shijiazhuang City, Hebei Province, China.

\section{Xiaoyun Zhao}

Department of Pulmonary and Critical Care Medicine, Tianjin Chest Hospital, Tianjin, China.

\section{Yingxiang Lin}

Department of Respiratory and Critical Care Medicine, Beijing Chaoyang Hospital, Capital Medical University, Beijing, China.

\section{Shu Zhang}

Department of Respiratory and Critical Care Medicine, Beijing Chaoyang Hospital, Capital Medical University, Beijing, China.

\section{Zhu Li}

Department of Respiratory Medicine and PCCM, The First Hospital of Hebei Medical University, 89 Donggang Road, Shijiazhuang City, Hebei Province, China.

\section{Yong Lu}

Department of Respiratory and Critical Care Medicine, Beijing Chaoyang Hospital, Capital Medical University, Beijing, China.

\section{Wen Wang}

Department of Respiratory and Critical Care Medicine, Beijing Chaoyang Hospital, Capital Medical University, Beijing, China.

\section{Juanni Gong}

Department of Respiratory and Critical Care Medicine, Beijing Chaoyang Hospital, Capital Medical University, Beijing, China.

\section{Yan Liu}

Department of Respiratory and Critical Care Medicine, Beijing Chaoyang Hospital, Capital Medical University, Beijing, China.

\section{Yanxia Yu}

Department of Respiratory and Critical Care Medicine, Beijing Chaoyang Hospital, Capital Medical University, Beijing, China.

\section{Bojun Li}

Department of Pulmonary and Critical Care Medicine, Tianjin Chest Hospital, Tianjin, China.

\section{Xiujuan Hu}


Department of Pulmonary and Critical Care Medicine, Tianjin Chest Hospital, Tianjin, China.

\section{Yuechuan Li}

Department of Pulmonary and Critical Care Medicine, Tianjin Chest Hospital, Tianjin, China.

\section{Zhaohui Tong ( $\nabla$ tongzhaohuicy@sina.com )}

Department of Respiratory and Critical Care Medicine, Beijing Chaoyang Hospital, Capital Medical University, Beijing, China.

\section{Research}

Keywords: Pulmonary Disease, Chronic Obstructive, Pulmonary Rehabilitation, neuromuscular electrical stimulation, Sixminute Walk Distance

Posted Date: August 13th, 2020

DOI: https://doi.org/10.21203/rs.3.rs-58117/v1

License: (c) (i) This work is licensed under a Creative Commons Attribution 4.0 International License. Read Full License 


\section{Abstract}

Background: Chronic obstructive pulmonary disease (COPD) is a progressive lung disease, which might be improved by neuromuscular electrical stimulation. To date, no trials of intervention of inspiratory plus expiratory neuromuscular electrical stimulation have been conducted. This study aimed to evaluate the effect and safety of in patients with severe COPD.

Methods: In this prospective, multicenter controlled trial, 120 stable patients with severe COPD who received standard medical treatment were assigned 1:1 to receive either inspiratory plus expiratory neuromuscular electrical stimulation (study intervention) or stimulation of the phrenic nerve, called diaphragm pacing (control intervention). Intention-to-treat analysis was carried out. The primary outcome was to analyze the changes in functional exercise capacity, estimated as six-minute walk distance (6MWD), following four weeks of electrical stimulation intervention.

Results: The change in 6MWD was greater in the study intervention $(65.53 \pm 39.45 \mathrm{~m})$ than in the control intervention $(26.66 \pm 32.65 \mathrm{~m})$. The mean between-group difference at four weeks was $29.07 \mathrm{~m}([95 \% \mathrm{Cl}, 16.098$ to 42.035$] ; \mathbb{\nabla}<0.001)$. There was no significant between-group difference in secondary (modified Medical Research Council, forced expiratory volume in 1 second $\left(\mathrm{FEV}_{1}\right), \mathrm{FEV}_{1} \%$ predicted, and $\mathrm{FEV}_{1}$ ratio forced vital capacity $(\mathrm{FEV} / \mathrm{FVC})$ ) outcomes after four weeks

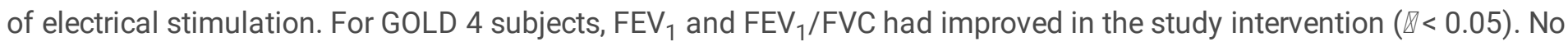
electrical stimulation-related serious adverse events were observed in either group.

Conclusion: Functional exercise capacity were significantly improved in the study intervention in stable patients with severe COPD after four weeks of treatment.

Trial registration: ChiCTR, ChiCTR2000032681. Registered 6 May 2020- Retrospectively registered, http://www.chictr.org.cn/showproj.aspx?proj=53086.

\section{Background}

At present, chronic obstructive pulmonary disease (COPD) is a significant contributor to global morbidity and mortality, and carries a significant economic and social burden $[1,2]$. Respiratory muscle dysfunction is a common consequence of COPD [3]. Studies have shown that respiratory muscle weakness is associated with an increased mortality rate in COPD patients [4] and is a risk factor for readmission to the hospital due to exacerbation [5].

Pulmonary rehabilitation plays an important role in COPD patients. Previous studies have shown that inspiratory muscle training plus expiratory muscle training can enhance respiratory muscle strength and improve exercise capacity in subjects with severe to very severe COPD [6]. However, engaging in active exercise training is restricted in COPD patients with prominent ventilation dysfunction. As a result, studies in other alternative methods for respiratory muscle contraction, such as neuromuscular electrical stimulation therapy, which does not cause dyspnea and minimize cardiocirculatory damage, has been concerned [7].

Historically, transcutaneous electrical diaphragmatic stimulation, a form of inspiratory neuromuscular electrical stimulation, has been shown to increase respiratory minute volume in patients with COPD [8]. Studies have confirmed that abdominal electrical stimulation can improve ventilation parameters such as peak expiratory flow rate in patients with COPD [9]. However, until now, there have been no studies on evaluation of the inspiratory plus expiratory neuromuscular (diaphragmatic and abdominal muscles) electrical stimulation for COPD individuals.

This trial aimed to determine the effectiveness and effect of inspiratory plus expiratory neuromuscular electrical stimulation on functional exercise capacity in severe COPD patients. The trial engaged a novel strategy that stimulating 
diaphragm and abdominal muscle (rectus abdominis muscle and obliquus externus abdominis muscle) during inspiration and expiration, respectively. We hypothesized that patients who received inspiratory plus expiratory neuromuscular electrical stimulation after four weeks would show an increase in functional exercise capacity compared with patients who received stimulation of the phrenic nerve, called diaphragm pacing.

\section{Material And Methods}

\section{Study design and participants}

This was a multicenter, prospective and randomized controlled trial investigating the effects of inspiratory plus expiratory neuromuscular neuromuscular electrical stimulation over diaphragm pacing.

Patients were enrolled from Beijing Chaoyang Hospital affiliated to Capital Medical University, Tianjin Chest Hospital, and the First Hospital of Hebei Medical University between May 2018 and September 2019. Eligible patients fulfilled severe COPD [10]. The inclusion criteria were: 1) Had capacity to consent and signed written informed consent; 2) Aged between 40 and 75 years old; 3) A spirometrically defined diagnosis of COPD with GOLD criteria; a grade 1-3 modified Medical Research Council (mMRC) dyspnea score; and a post-bronchodilator forced expiratory volume in 1 second ratio forced vital capacity $\left.\left(\mathrm{FEV}_{1} / \mathrm{FVC}\right)<0.70 ; 4\right)$ The severity of airflow restriction in COPD subjects met the following conditions: $\mathrm{FEV}_{1} / \mathrm{FVC}<0.70$ with severe respiratory impairment of $\mathrm{FEV}_{1} \%$ predicted $<50 \%$ after subjects inhaled bronchodilator; 5) The modified Medical Research Council (mMRC) score of the subjects was 1-3. The exclusion criteria were: 1) Unable to complete the experiment; 2) Contraindications of respiratory neuromuscular stimulator or diaphragm pacemaker; 3) An acute exacerbation event four weeks prior screening period; 4) Suffer from other lung diseases, such as pneumothorax, tuberculosis, lung cancer; 5) Under the rest condition of breathing ambient air at sea level: $\mathrm{PaO}_{2}<60 \mathrm{mmHg}, \mathrm{PaCO}_{2}>$ $50 \mathrm{mmHg}$; 6) Subjects who were using invasive or noninvasive mechanical ventilation; 7) According to the NYHA heart function classification, subjects with heart function level III-IV; 8) Unstable angina or myocardial infarction occurred within 30 days before screening; 9 ) Renal function: according to the CKD-EPI formula, the calculated creatinine clearance rate is $\leq 30 \mathrm{ml}$ / min during the screening period; 10) Liver function: at the screening stage, AST, ALT or total bilirubin $\geq$ 1.5 times of the upper limit of normal value; 11) Other clinical trials were conducted within 30 days before the screening period; 12) Other conditions, mental disorders, cognitive disorders, etc. that can't cooperate with study.

This protocol was approved by the ethics committee of these three hospitals, and registerd as ChiCTR2000032681. All participants provided written informed consent.

\section{Randomisation Procedure}

All enrolled patients were randomized 1:1 to either the inspiratory plus expiratory neuromuscular electrical stimulation (study intervention) or diaphragm pacing (control intervention) using stratified block randomisation. Intervention assignments were generated using the statistical analysis SAS version 9.4 (SAS Institute Inc., Cary, NC) statistical software and communicated using sealed opaque envelopes.

\section{Data Collection}

Demographic data mainly included the age, gender, body mass index and general information were collected. Clinical data included patient medical history, vital signs, laboratory test data, 6-minute walk distance (6MWD) [11, 12], mMRC dyspnea score [13], spirometry [14], arterial blood gas, and diaphragm motions during quiet breathing and deep breathing

[15]. These measurements were recorded before, after two-week and four-week periods of electrical stimulation. 


\section{Study Intervention}

For the study intervention, subjects used a inspiratory plus expiratory neuromuscular electrical stimulation (by Yaguo Technology Co., Ltd, Beijing, China). The device contains one diaphragm stimulation and two abdominal muscle stimulations. For control intervention, patients were treated with an diaphragm electrical stimulation.

The procedures were conducted by a doctor according to the instructions. For each patient, the stimulation time was 30 minutes a day, continuous for four weeks. Details on the instructions of electrical stimulation procedure are provided in online data supplement.

\section{Outcome Analysis}

The primary outcome was the increase in 6MWD from the baseline to four weeks following stimulation. Secondary outcomes were: 1) improvement of pulmonary function; 2) symptoms of dyspnea; 3) changes of diaphragmatic motions during quiet breathing and deep breathing after four weeks of electrical stimulation between two groups. Safety endpoints were adverse events observed in either group during study period.

\section{Sample Size}

Subjects increased 6MWD by 35 meters with inspiratory muscle training in a previous study [16]. A 20 meters more increase in primary outcome of walk distance in study intervention compared with the control intervention would be expected in our study. The power was set to $80 \%$ at the 0.05 significance level. The estimated sample size for each group was fifty, and considering a loss rate of less than $20 \%$, the enrolled number in each group was sixty.

\section{Statistical Methods}

SAS 9.4 software was used for statistical analysis. A $P$ value $<0.05$ was considered statistically significant. The primary outcome analysis was done on an intention-to-treat basis with all randomly assigned patients .

Results were expressed as the mean \pm SD for the normally distributed variables. Intra-group comparisons of the quantitative data were performed using the paired Student's $t$-test and The Wilkinson rank test for non-normal distribution. Inter-group comparisons were performed using unpaired Student $t$-tests or the Mann-Whitney $U$ test for variables with non-normal distribution. Categorical variables were presented as percentages, and compared using ChiSquared tests or Fisher's test. Other analyses include subgroup patients in GOLD 3 and GOLD 4 between two groups [10].

\section{Results}

\section{Recruitment and baseline characteristics}

The flow of recruitment used in this study is shown in Fig. 1. Of the 162 people screened for eligibility, 37 did not meet the inclusion criteria, 1 had one exclusion criteria, four declined participation and a total of 120 patients were randomly assigned either to study intervention $(N=60)$ or to control intervention $(N=60)$. Five discontinued the intervention: four withdrew consent, and one due to sufferd from influeza during study piorid. All randomized patients were included in the intent to treatment analyses. 
Participants had a mean age of $64.59 \pm 5.69$ years, of whom 110 (91.6\%) were males, and mean 6-min walk distance of $431.28 \pm 57.06 \mathrm{~m}$. All participants had a mean value of $\mathrm{FEV}_{1} \%$ predicted $40.82 \%(32.00,47.00)$. At enrollment, $78.5 \%$ of the participants were receiving inhaled anticholinergic agents or long-acting $\beta 2$ adrenergic agonists. The baseline characteristics of 120 randomized patients were similar across the two intervention groups (shown in Table 1). 
Table 1

Baseline characteristics for both groups according to allocation

\begin{tabular}{|c|c|c|c|}
\hline Variables & $\begin{array}{l}\text { Study intervention } \\
(N=60)\end{array}$ & $\begin{array}{l}\text { control intervention } \\
(\mathrm{N}=60)\end{array}$ & $P$ \\
\hline \multicolumn{4}{|l|}{ Anthropometric data } \\
\hline Age (years) * & $65.7(61.66,68.33)$ & $64.7(60.93,69.26)$ & 0.910 \\
\hline Gender: male N (\%) ${ }^{\dagger}$ & $53(88.33 \%)$ & $57(95.00 \%)$ & 0.186 \\
\hline Height $(\mathrm{cm})$ * & $170.00(166.00,173.00)$ & $170.00(165.00,172.50)$ & 0.499 \\
\hline Weight $(\mathrm{kg})^{\ddagger}$ & $67.74 \pm 10.95$ & $66.17 \pm 9.45$ & 0.401 \\
\hline \multicolumn{4}{|l|}{ Co-morbidity, N (\%) } \\
\hline Hypertension $^{\dagger}$ & $7(11.67 \%)$ & $3(5.00 \%)$ & 0.186 \\
\hline Ischemic heart disease $^{\dagger}$ & $4(6.66 \%)$ & $7(11.67 \%)$ & 0.194 \\
\hline Heart failure $^{\dagger}$ & $4(6.66 \%)$ & $7(11.67 \%)$ & 0.194 \\
\hline Smoking status: never / current N (\%) ${ }^{\dagger}$ & $11(18.33 \%) / 49$ (81.67\%) & $9(15.00 \%) / 51(85.00 \%)$ & 0.624 \\
\hline \multicolumn{4}{|l|}{ Medical treatment, N (\%) } \\
\hline Inhaled long-acting bronchodilators (\%) ${ }^{\dagger}$ & $49(83.05 \%)$ & $45(75.00 \%)$ & 1.000 \\
\hline 6-minute walking distance $(\mathrm{m})^{\ddagger}$ & $423.27 \pm 59.34$ & $439.30 \pm 53.98$ & 0.124 \\
\hline \multicolumn{4}{|l|}{ Spirometry } \\
\hline $\mathrm{FEV}_{1}(\mathrm{~L})^{\ddagger}$ & $1.15 \pm 0.27$ & $1.10 \pm 0.26$ & 0.316 \\
\hline $\mathrm{FEV}_{1} \%$ predicted (\%) * & $40.92(32.10,47.40)$ & $40.40(31.97,45.75)$ & 0.495 \\
\hline $\mathrm{FVC}(\mathrm{L})^{\ddagger}$ & $2.50 \pm 0.52$ & $2.45 \pm 0.55$ & 0.570 \\
\hline $\mathrm{FEV}_{1} / \mathrm{FVC}(\%)$ * & $43.80(39.83,53.66)$ & $45.24(39.75,52.31)$ & 0.998 \\
\hline Maxima ventilation volume $(\mathrm{L} / \mathrm{min})^{\ddagger}$ & $44.97 \pm 13.74$ & $42.68 \pm 13.10$ & 0.384 \\
\hline Peak expiratory flow $(\mathrm{L} / \mathrm{s})^{\ddagger}$ & $3.47 \pm 1.09$ & $3.39 \pm 1.05$ & 0.686 \\
\hline mMRC grade1 $\mathrm{N}(\%)^{\dagger}$ & $31(51.67 \%)$ & $27(45.00 \%)$ & 0.383 \\
\hline mMRC grade $2 \mathrm{~N}(\%)^{\dagger}$ & $20(33.33 \%)$ & $27(45.00 \%)$ & \\
\hline mMRC grade3 $\mathrm{N}(\%)^{\dagger}$ & $9(15.00 \%)$ & $6(10.00 \%)$ & \\
\hline $\mathrm{PaCO}_{2}(\mathrm{mmHg})$ * & $40.80(38.50,43.20)$ & $39.55(36.85,43.05)$ & 0.233 \\
\hline $\mathrm{PaO}_{2}(\mathrm{mmHg})$ * & $77.20(72.00,84.95)$ & $77.60(73.00,84.15)$ & 0.787 \\
\hline Diaphragm motion in quiet breathing $(\mathrm{cm})^{\ddagger}$ & $2.26 \pm 0.69$ & $2.29 \pm 0.60$ & 0.789 \\
\hline
\end{tabular}




\begin{tabular}{|c|c|c|c|}
\hline Variables & $\begin{array}{l}\text { Study intervention } \\
(\mathrm{N}=60)\end{array}$ & $\begin{array}{l}\text { control intervention } \\
(N=60)\end{array}$ & $P$ \\
\hline Diaphragm motion in deep breathing $(\mathrm{cm})^{\ddagger}$ & $4.67 \pm 1.22$ & $4.52 \pm 0.94$ & 0.450 \\
\hline
\end{tabular}

\section{Outcomes}

For the primary outcome, after four weeks of electrical stimulation, a statistically and clinically significant increase in 6minute walk distance was observed in the study intevention $(65.53 \pm 39.45 \mathrm{~m}, P<0.001)$, twice greater improvement than control intervention $(26.66 \pm 32.65 \mathrm{~m}, P<0.05)$ The between-group comparisons of the changes in the walk distance showed significant differences $(29.07 \mathrm{~m}(95 \% \mathrm{Cl} 16.098,42.035), P<0.001)$. The trend of measurements differences between two groups is shown in Fig. 2.

Table 2 summarises the results of the major secondary outcomes. For the seconsary outcomes, after four weeks of electrical stimulation, patients in the study intervention had greater improvement in mMRC grade than in the control intervention, but there was no statistical difference ( $-0.3 \pm 0.57$ vs. $-0.22 \pm 0.53, P=0.526)$. We observed no significant differences in the intra-group for the $\mathrm{FEV}_{1}$ \% predicted, FVC, $\mathrm{FEV}_{1} / \mathrm{FVC}$, and $\mathrm{MVV}$ values following four weeks of intervention. Although there were no statistical differences in the diaphragm motion, there was a twice improvement in the study intervention when compared to the control intervention in quite breathing $(0.13 \pm 0.98 \mathrm{~cm}$ and $0.06 \pm 0.77 \mathrm{~cm}$, respectively, $P=0.672$ ). 
Table 2

Variables of subjects in major secondary outcome measures at four weeks after intervention according to group allocation

\begin{tabular}{|c|c|c|c|c|c|c|c|}
\hline \multirow[t]{2}{*}{ Variables } & \multicolumn{3}{|c|}{ Study intervention $(\mathrm{N}=57)$} & \multicolumn{3}{|c|}{ Control intervention $(\mathrm{N}=58)$} & \multirow{2}{*}{$\begin{array}{l}\text { Comparisons } \\
\text { of changes }\end{array}$} \\
\hline & $\begin{array}{l}\text { Pre- } \\
\text { intervention }\end{array}$ & $\begin{array}{l}\text { Post- } \\
\text { intervention }\end{array}$ & $\begin{array}{l}\text { Post- } \\
\text { pre }\end{array}$ & $\begin{array}{l}\text { Pre- } \\
\text { intervention }\end{array}$ & $\begin{array}{l}\text { Post- } \\
\text { intervention }\end{array}$ & Post-pre & \\
\hline \multicolumn{8}{|l|}{ Spirometry } \\
\hline $\mathrm{FEV}_{1}(\mathrm{~L}) *$ & $1.15 \pm 0.27$ & $1.21 \pm 0.32$ & $\begin{array}{l}0.06 \\
\pm 0.17\end{array}$ & $1.10 \pm 0.26$ & $1.19 \pm 0.32$ & $\begin{array}{l}0.08 \pm \\
0.17\end{array}$ & 0.553 \\
\hline $\begin{array}{l}\mathrm{FEV}_{1} \% \text { predicted } \\
(\%)+\end{array}$ & $\begin{array}{l}40.83 \\
(32.80 \\
47.20)\end{array}$ & $\begin{array}{l}39.80 \\
(34.60 \\
49.51)\end{array}$ & $\begin{array}{l}1.50 \\
(-2.10 \\
6.30)\end{array}$ & $\begin{array}{l}40.40 \\
(32.20 \\
45.20)\end{array}$ & $\begin{array}{l}42.05 \\
(34.40 \\
50.30)\end{array}$ & $\begin{array}{l}1.75 \\
(-1.20 \\
5.20)\end{array}$ & 0.673 \\
\hline $\mathrm{FVC}(\mathrm{L})$ * & $2.50 \pm 0.52$ & $2.63 \pm 0.47$ & $\begin{array}{l}0.12 \\
\pm 0.32\end{array}$ & $2.46 \pm 0.55$ & $2.60 \pm 0.50$ & $\begin{array}{l}0.14 \pm \\
0.35\end{array}$ & 0.725 \\
\hline $\mathrm{FEV}_{1} / \mathrm{FVC}(\%)+$ & $\begin{array}{l}43.71 \\
(40.50 \\
53.63)\end{array}$ & $\begin{array}{l}43.63(38.33 \\
53.52)\end{array}$ & $\begin{array}{l}-0.12 \\
(-3.15 \\
3.26)\end{array}$ & $\begin{array}{l}45.24 \\
(39.83 \\
53.03)\end{array}$ & $\begin{array}{l}44.91 \\
(38.79 \\
52.89)\end{array}$ & $\begin{array}{l}0.20 \\
(-4.46 \\
3.71)\end{array}$ & 0.717 \\
\hline $\begin{array}{l}\text { Maxima } \\
\text { ventilation } \\
\text { volume }(\mathrm{L} / \mathrm{min}) \\
\text { * }\end{array}$ & $\begin{array}{l}44.97 \pm \\
13.74\end{array}$ & $\begin{array}{l}48.03 \pm \\
13.42\end{array}$ & $\begin{array}{l}3.37 \\
\pm \\
10.75\end{array}$ & $\begin{array}{l}42.74 \pm \\
13.23\end{array}$ & $\begin{array}{l}45.08 \pm \\
14.45\end{array}$ & $\begin{array}{l}2.97 \pm \\
9.07\end{array}$ & 0.503 \\
\hline $\begin{array}{l}\text { Peak expiratory } \\
\text { flow }(\mathrm{L} / \mathrm{s}) \text { * }\end{array}$ & $3.47 \pm 1.11$ & $3.70 \pm 1.25$ & $\begin{array}{l}0.23 \\
\pm 0.77\end{array}$ & $3.40 \pm 1.06$ & $3.61 \pm 1.08$ & $\begin{array}{l}0.21 \pm \\
0.68\end{array}$ & 0.982 \\
\hline $\mathrm{mMRC}^{\star}$ & $1.63 \pm 0.74$ & $1.33 \pm 0.61$ & $\begin{array}{l}-0.30 \\
\pm 0.57\end{array}$ & $1.65 \pm 0.66$ & $1.42 \pm 0.56$ & $\begin{array}{l}-0.22 \pm \\
0.53\end{array}$ & 0.526 \\
\hline $\begin{array}{l}\mathrm{mMRC} \text { grade } 0 \\
\mathrm{~N}(\%) \ddagger\end{array}$ & $0(0.00 \%)$ & $1(1.75 \%)$ & & $0(0.00 \%)$ & $0(0.00 \%)$ & & \\
\hline $\begin{array}{l}\mathrm{mMRC} \text { grade } 1 \\
\mathrm{~N}(\%) \ddagger\end{array}$ & $\begin{array}{l}29 \\
(50.88 \%)\end{array}$ & $39(68.42 \%)$ & & $\begin{array}{l}26 \\
(44.83 \%)\end{array}$ & $35(60.34 \%)$ & & \\
\hline $\begin{array}{l}\text { mMRC grade2 } \\
N(\%) \ddagger\end{array}$ & $\begin{array}{l}20 \\
(35.09 \%)\end{array}$ & $14(24.56 \%)$ & & $26(44.83 \%)$ & $21(36.21 \%)$ & & \\
\hline $\begin{array}{l}\text { mMRC grade3 } \\
N(\%) \neq\end{array}$ & $8(14.04 \%)$ & $3(5.26 \%)$ & & $6(10.34 \%)$ & $2(3.45 \%)$ & & \\
\hline $\begin{array}{l}\mathrm{PaCO}_{2}(\mathrm{mmHg}) \\
\dagger\end{array}$ & $\begin{array}{l}40.80 \\
(38.60 \\
43.40)\end{array}$ & $\begin{array}{l}41.60(39.30 \\
43.90)\end{array}$ & $\begin{array}{l}1.20 \\
(-1.10 \\
2.50)\end{array}$ & $\begin{array}{l}39.15 \\
(36.70 \\
42.80)\end{array}$ & $\begin{array}{l}39.90 \\
(36.50 \\
44.10)\end{array}$ & $\begin{array}{l}0.60(-2.30 \\
2.60)\end{array}$ & 0.524 \\
\hline $\begin{array}{l}\mathrm{PaO}_{2}(\mathrm{mmHg}) \\
+\end{array}$ & $\begin{array}{l}77.20 \\
(72.50 \\
85.10)\end{array}$ & $\begin{array}{l}78.30 \\
(74.10 \\
84.80)\end{array}$ & $\begin{array}{l}1.10 \\
(-3.40 \\
5.30)\end{array}$ & $\begin{array}{l}77.70 \\
(73.00 \\
84.20)\end{array}$ & $\begin{array}{l}79.20 \\
(72.50 \\
84.50)\end{array}$ & $\begin{array}{l}1.00 \\
(-5.60 \\
6.40)\end{array}$ & 0.566 \\
\hline $\begin{array}{l}\text { Diaphragm } \\
\text { motion in quiet } \\
\text { breathing }(\mathrm{cm}) \\
\star\end{array}$ & $2.26 \pm 0.69$ & $2.39 \pm 0.76$ & $\begin{array}{l}0.13 \\
\pm 0.98\end{array}$ & $2.28 \pm 0.60$ & $2.34 \pm 0.63$ & $\begin{array}{l}0.06 \pm \\
0.77\end{array}$ & 0.672 \\
\hline $\begin{array}{l}\text { Diaphragm } \\
\text { motion in deep } \\
\text { breathing (cm) } \\
\star\end{array}$ & $4.70 \pm 1.24$ & $5.01 \pm 0.93$ & $\begin{array}{l}0.31 \\
\pm 1.27\end{array}$ & $4.53 \pm 0.96$ & $4.85 \pm 0.98$ & $\begin{array}{l}0.32 \pm \\
1.03\end{array}$ & 0.938 \\
\hline
\end{tabular}




\section{Subgroup Analysis}

We subgrouped the subjects according to the classification of airflow limitation severity of $\mathrm{FEV}_{1} \%$ predicted at baseline. Forty-eight subjects in study intervention and forty-nine subjects in the control intervention had $\mathrm{FEV}_{1} \%$ predicted among $30 \% \leq \mathrm{FEV}_{1} \%$ predicted $<50 \%$, representing GOLD 3 . Twelve and eleven subjects were GOLD 4 (FEV $\mathrm{FF}_{1}$ predicted $\left.<30 \%\right)$ in study intervention and control intervention, respectively. There was no significant differences in baseline variables of subgroup patients between groups. Details of baseline are outlined in Tables E1 of the Online Data Supplement). For GOLD 3 subjects, 6-min walk distance was significantly increased in the study intervention than in the control intervention following four-week electrical stimulation ( $495.88 \pm 74.61 \mathrm{~m}$ vs. $469.04 \pm 52.59 \mathrm{~m}, P=0.049$ ), but there was no differences of secondary outcomes after four-week intervention between groups (details are outlined in Tables E2 of the Online Data Supplement). For GOLD4 subjects, no significant differences were found in baseline variables (details are outlined in Tables E3 of the Online Data Supplement), however, FEV $1, \mathrm{FEV}_{1}$ \%predicted, and $\mathrm{FEV}_{1} / \mathrm{FVC}$ levels had improved in the study intervention ( $P \otimes 0.05$ ) (Table 3). The increasing trend of pulmonary function in GOLD 4 group following two and four-week electrical stimulation is shown in Fig. 3.

Table 3

Estimates of the effect of pulmonary function of GOLD4 at four weeks

\begin{tabular}{|c|c|c|c|}
\hline Variables & $\begin{array}{l}\text { Study intervention } \\
(\mathrm{N}=12)\end{array}$ & $\begin{array}{l}\text { Control intervention } \\
(\mathrm{N}=9)\end{array}$ & $P$ \\
\hline 6-minute walking distance $(\mathrm{m})$ * & $472.37 \pm 63.71$ & $447.44 \pm 52.68$ & 0.353 \\
\hline \multicolumn{4}{|l|}{ mMRC } \\
\hline mMRC grade0 $\mathrm{N}(\%) \dagger$ & $1(8.33 \%)$ & $0(0.00 \%)$ & 0.227 \\
\hline mMRC grade1 $\mathrm{N}(\%) \dagger$ & $5(41.67 \%)$ & $2(22.22 \%)$ & \\
\hline mMRC grade2 $\mathrm{N}(\%) \dagger$ & $5(41.67 \%)$ & $6(66.67 \%)$ & \\
\hline mMRC grade3 $\mathrm{N}(\%) \dagger$ & $1(8.33 \%)$ & $1(11.11 \%)$ & \\
\hline \multicolumn{4}{|l|}{ Spirometry } \\
\hline $\mathrm{FEV}_{1}(\mathrm{~L}) *$ & $0.92 \pm 0.20$ & $0.73 \pm 0.12$ & 0.018 \\
\hline $\mathrm{FEV}_{1} \%$ predicted $(\%) \neq$ & $29.30(25.89,34.40)$ & $25.03(20.70,26.40)$ & 0.005 \\
\hline $\mathrm{FVC}(\mathrm{L})$ * & $2.34 \pm 0.43$ & $2.14 \pm 0.33$ & 0.259 \\
\hline $\mathrm{FEV}_{1} / \mathrm{FVC}(\%) \ddagger$ & $38.90(34.71,42.56)$ & $38.02(28.39,39.54)$ & 0.180 \\
\hline Maxima ventilation volume $(\mathrm{L} / \mathrm{min})$ * & $37.05 \pm 6.84$ & $31.06 \pm 5.93$ & 0.050 \\
\hline Peak expiratory flow $(\mathrm{L} / \mathrm{s})$ * & $2.88 \pm 0.81$ & $2.81 \pm 0.61$ & 0.849 \\
\hline $\mathrm{PaCO}_{2}(\mathrm{mmHg}) \neq$ & $43.50(41.00,45.15)$ & $39.80(37.30,45.20)$ & 0.276 \\
\hline $\mathrm{PaO}_{2}(\mathrm{mmHg}) \neq$ & $73.05(70.45,79.40)$ & $79.20(73.70,85.80)$ & 0.431 \\
\hline Diaphragm motion in quiet breathing $(\mathrm{cm})$ * & $2.16 \pm 0.62$ & $2.37 \pm 0.78$ & 0.493 \\
\hline Diaphragm motion in deep breathing $(\mathrm{cm})$ * & $4.84 \pm 1.17$ & $5.23 \pm 0.51$ & 0.317 \\
\hline
\end{tabular}

\section{Adverse Events}


It was showed that data on the occurrence of adverse events related to the intervention was minor. Analysis of these two intervention was demonstrated no risk difference between the two groups. The proportion of participants who had adverse events was similar between the groups, nine (15.00\%) in the study intervention and nine $(15.00 \%)$ in the control intervention $(P=1.0)$. One participant in the study intervention suffered from influenza during the treatment and quit the trial due to hospital admission. None of these patients had any acute exacerbations that required antibiotics during the study period. Details of Adverse Events are outlined in Tables E4 of the Online Data Supplement.

\section{Discussion}

This study aimed to evaluate whether the electrical stimulation of the inspiratory plus expiratory muscle has an advantage over the electrical stimulation of the diaphragm alone. Our study showed that after four weeks of treatment, compared with control intervention, inspiratory plus expiratory neuromuscular electrical stimulation significantly improved the functional exercise capacity of patients with severe COPD; this was primarily observed in the GOLD3 subgroup.

This study was designed to be a multicenter, randomized, and controlled trial, which was not blind, as there were significant differences in function and appearance between the study and control intervention.

At present, respiratory muscle electrical stimulation To some extent replace muscle training pulmonary rehabilitation for some particular COPD patients, which can improve the patient's respiratory muscle endurance and strength [9]. A systematic retrospective study on respiratory muscle training recommends that each training time lasts 20-30 minutes [17]. The frequency of these two instruments used in this clinical trial were set to $40 \mathrm{~Hz}$ in beginning, and treatment time of this clinical trial was also set at 30 minutes per day, which not only increased respiratory muscle strength but also avoided respiratory muscle fatigue. Previous clinical trials have shown that neuromuscular electrical stimulation can improve respiratory muscle strength after four weeks of intervention [18]. Therefore, the outcome of effect sobservation was set to four weeks following intervention.

The 6-minute walk distance developed by the American Thoracic Society is a functional exercise test that is easy to operate, and reflects the patients' daily exercise status with better accuracy [12]. In this study, 6MWD after four weeks of treatment was used as primary observational variable to evaluate the therapeutic effects of electrical stimulation on patients with severe COPD.

In this trial, the improvement in 6MWD in the study intervention (65.53 $\pm 39.45 \mathrm{~m})$ was more significant than that in the control intervention $(26.66 \pm 32.65 \mathrm{~m})$. It has been reported by previous researchers that the increase of $6 \mathrm{MWD}$ in the ranged between $25 \mathrm{~m}$ and $33 \mathrm{~m}$ in inspiratory neuromuscular elctrostimulation treatment $[19,20]$. The reason why there was a better 6MWD improvement in our study in the study intervention may be because it combines the electrical stimulation of both diaphragm and abdominal muscles. These findings are consistent with the results of previous studies [21]. A meta-analysis showed that in subjects, the combination of inspiratory muscle training combined with expiratory muscle training is more effective in increasing exercise performance compared with inspiratory muscle training alone [22].

It is known that expiratory muscles are activated during expiration in subjects with COPD, mostly at the end of expiration [23]. Inspiratory plus expiratory neuromuscular electrical stimulation should be more helpful than inspiratory neuromuscular electrical stimulation alone in reducing the symptoms of dyspnea. Our study showed that the mMRC score of the study intervention had more improvement than that of the control intervention. Although there was no statistical difference between the two groups. The lack of statistical differences may be related to the short trial period and the small number of patients. Elctrostimulation might prevent muscle function deterioration [24], improve muscle strength and dyspnea in individuals with a low body mass index [25].

Page $11 / 18$ 
Although the therapeutic effects of COPD are often judged by the changes in $\mathrm{FEV}_{1}$, there were no significant improvements in pulmonary functions after four-week intervention in our study. Weiner et al. demonstrated that when inspiratory muscle training is used alone, there were no improvements in maximum expiratory pressure [26]. But authors observed that inspiratory muscle training combined with expiratory muscle training provided higher gains in the maximum expiratory pressure and maximum inspiratory pressure compared to the control groups [27]. These studies demonstrated the importance of improving both inspiratory and expiratory muscles in subjects with COPD. Meanwhile, according to the results of previous studies, short-term pulmonary rehabilitation may not have a significant impact on $\mathrm{FEV}_{1}[28]$. Longer-term clinical trials may be performed in the future to validate this hypothesis.

The main expected benefit of intervention in patients with severe COPD is likely to be related to muscle activity and reinforcement. In our study, although the increase of diaphragm motion did not amount to a statistically significant difference, we observed more increase in diaphragm motion in the quiet breathing and deep breathing after four weeks of study intervention. Some reasons may explain this. First, Prieur et al. evaluated the effects of electrical stimulation on skeletal muscle oxygenation in patients with COPD [29]. They determined that deoxygenations and increase in oxygen uptake of muscle and tissue occurred during electrical stimulation. These deoxygenations might reflect a lower level of voluntary muscle activity during the electrical stimulation. This suggests that the metabolic load of the muscle was increased by electrical stimulation. Besides, electrical stimulation can improve muscle strength in peripheral muscles [25].

Although our trial was not extensive enough to detect small changes in secondary outcomes, by subgrouping the participants into GOLD 3 vs. GOLD 4, we could explore whether the effects differed between participants with different severities, and the results showed a trend of favorable outcomes in GOLD 4 patients. It suggested that individuals with lower pulmonary function may achieve significant gains in pulmonary function compared study intervention with control intervention. This may indicate that patients with a high level of impairment might respond favorably, while the trend of increase in diaphragm motion range might explain this response. The small number of participants included and the short duration of intervention might explan other unfavorable results.

There were no severe adverse events related to the intervention in the both group. There might be one adverse event related to the intervention in control group. It can be seen that the risk of electrical stimulation is minimal, and adverse events related to electrical stimulation are few and can be accepted by most subjects. These results reveal that this technique was well tolerated by the patients regardless of their disease severity.

The improvement in respiratory muscle strength is important for patients with COPD. Pulmonary rehabilitation has been demonstrated to reduce dyspnea, increase exercise capacity, and improve the quality of life in individuals with COPD [11, 6]. Respiratory muscle training is an effective way for COPD patients to recover. However, many training exercises require patients to do active work, resulting in poor patient compliance and limited treatment effects. Furthermore, many patients could not participate in these training sessions due to personal reason. Neuromuscular electrical stimulation is a passive training method that allows selected muscles to contract without the need for active work. It has been found that electrical stimulation could partly mimic the muscle training procedure and had a similar partial effect on muscle function [21].

Based on this clinical trial, inspiratory plus expiratory neuromuscular electrical stimulation represents a noval form of neuromuscular electrical stimulation, which is a promising pulmonary rehabilitation mode. Electrical stimulation of respiratory muscles has been applied in the treatment of other diseases, and a study found that functional electrical stimulation of abdominal muscles can shorten ventilation duration and ICU length of staying in mechanically ventilated patients [30]. Further study can be applied to evaluate effect of electrical stimulation in critically ill patients.

Research limitations 
There are some limitations in the present study. First, the 6MWD of the participants in our trial seemed to be higher when compared to those of European patients. One reason for this discrepancy might be because all participants were recruited from stable outpatient groups. In the multicenter study reported by Waschki et al., participants achieved a mean 6MWD of $364 \mathrm{~m}$ with a similar FEV 1 level, which may be biased to relatively severe patients [31]. Future study needs to recruit subjects with lowered functional exercise capacity. Second, our study took only four weeks and did not include a longer observation and follow-up period. Based on this research, future work should consider longer programs of intervention. Third, we did not take into account improvement conditions of muscles, functional performance, symptoms rather than dyspnea, and other health-related changes in quality of life. Future studies should preferably be designed to permit more effects to be perceived.

\section{Conclusion}

The preliminary results demonstrated an advantage of improving functional exercise capacity in the inspiratory plus expiratory neuromuscular electrical stimulation in severe stable COPD patients after four weeks of treatment. Our study further consolidates the important role of neuromuscular electrical stimulation in pulmonary rehabilitation. More extensive, long-term studies are necessary to confirm the clinical and functional benefits of this technique and to define the precise therapeutic indications.

\section{Abbreviations}

COPD, chronic obstructive pulmonary disease; 6MWD, six-minute walk distance; $F_{1} V_{1}$, forced expiratory volume in 1 second; FVC, forced vital capacity; $F E V_{1} / F V C$, forced expiratory volume in 1 second ratio forced vital capacity; mMRC, modified Medical Research Council; MVV, maxima ventilation volume; $\mathrm{PaCO}_{2}$ arterial carbon dioxide tension; $\mathrm{PaO}_{2}$, arterial oxygen tension.

\section{Declarations}

Ethics approval and consent to participate: This study was approved by the Research Ethics Board of Beijing Chaoyang Hospital (2018-qi-12). Data were deidentified before analysis. All participants provided written informed consent.

\section{Consent for publication: Not applicable}

Availability of data and materials: The datasets used and/or analysed during the current study are available from the corresponding author on reasonable request

Competing interests: The authors declare that they have no competing interests.

Funding: This trial was supported by the Beijing Municipal Administration of Hospitals' Ascent Plan (ID: DFL20150302). Yaguo Technology Co., Ltd provided neuromuscular electrical stimulation equipment.

Authors' contributions: ZHT, XJW, WZS, XYZ, ZLZ substantial contributions to the conception or design of the work; YXL, $S Z, Z L, Y L, J N G, W W, Y L, Y X Y$ and BJL conducted the randomized controlled trial and data collection. ZLZ takes responsibility for the integrity of the data and the accuracy of the data analysis. ZLZ, XJW, WZS and XYZ contributed substantially Manuscript writing. All authors approved the final version of manuscript. ZHT reviewed the manuscript critically for important intellectual content and final approval of the version submitted for publication.

Acknowledgements: The authors are grateful for the support of all the doctors, nurses and clinical scientists who worked in the Beijing Chaoyang Hospital affiliated to Capital Medical University, Tianjin Chest Hospital, and the First Hospital of 
Hebei Medical University during the period of patient recruitment. We thank Xiaoyan Yan and Lingling Gao for statistical consultation. We would particularly thank all the subjects for their participation in this study. We also thank Yaguo Technology Co., Ltd for providing neuromuscular electrical stimulation equipment.

\section{References}

1. Murray LCJ. The State of US Health, 1990-2010. Jama the Journal of the American Medical Association. 2013;310(6):591-608.

2. Wang C, Xu J, Yang L, Xu Y, Zhang X, Bai C, et al. Prevalence and risk factors of chronic obstructive pulmonary disease in China (the China Pulmonary Health [CPH] study): a national cross-sectional study. Lancet. $2018 \mathrm{Apr}$ 28;391(10131):1706-17.

3. Weiner P, McConnell A. Respiratory muscle training in chronic obstructive pulmonary disease: inspiratory, expiratory, or both? Current Opinion in Pulmonary Medicine. 2005;11(2):140-44.

4. Hodgev VA, Kostianev SS. Maximal inspiratory pressure predicts mortality in patients with chronic obstructive pulmonary disease in a five-year follow-up. Folia medica. 2006;48(3-4):36-41.

5. Vilaró J, Ramirez-Sarmiento A, Martínez-Llorens JM, Mendoza T, Alvarez M, Sánchez-Cayado N, et al. Global muscle dysfunction as a risk factor of readmission to hospital due to COPD exacerbations. Respiratory medicine. 2010;104(12):1896-902.

6. Neves LF, Reis MH, Plentz RD, Matte DL, Coronel CC, Sbruzzi G. Expiratory and Expiratory Plus Inspiratory Muscle Training Improves Respiratory Muscle Strength in Subjects With COPD: Systematic Review. Respir Care. 2014;59(9):1381-88.

7. Chris ASM,JSS, Richard G, Linda Z, Carolyn N. R, et al. An official American Thoracic Society/European Respiratory Society statement: key concepts and advances in pulmonary rehabilitation. Am J Respir Crit Care Med. 2013;188(8):13-64.

8. Cancelliero-Gaiad KM, Daniela I, PCB F, Audrey GMR, Dirceu B-S. C. Acute effects of transcutaneous electrical diaphragmatic stimulation on respiratory pattern in COPD patients: cross-sectional and comparative clinical trial. Brazilian Journal of Physical Therapy. 2013;17(6):547-55.

9. Acqua AMD, Döhnert MB, Santos LJD. Neuromuscular Electrical Stimulation with Russian Current for Expiratory Muscle Training in Patients with Chronic Obstructive Pulmonary Disease The Society of Physical. Therapy Science. 2012;24(10):955-59.

10. Global Initiative for Chronic Obstructive Lung Disease (GOLD). 2020. wwwgoldcopdorg 8th May 2020.

11. Thierry EHA,ASM, A T, Véronique PM, Didier P. S, et al. An official European Respiratory Society/American Thoracic Society technical standard: field walking tests in chronic respiratory disease. Eur Respir J. 2014;44(6):1428-46.

12. Erratum. ATS Statement: Guidelines for the Six-Minute Walk Test. Am J Respir Crit Care Med. 2016;193(10):1185.

13. PJ DSAAAA. B, J B, BR C, et al. Global Strategy for the Diagnosis, Management, and Prevention of Chronic Obstructive Lung Disease: the GOLD science committee report 2019. The European respiratory journal. 2019;53(5).

14. Quanjer PH, Tammeling GJ, Coates JE, Perdersen OF, Yernault JC. Lung volumes and forced ventilatory flows. Report Working Party Standardization of Lung Function Tests, European Community for Steel and Coal. Official Statement of the European Respiratory Society. The European respiratory journal Supplement. 1993;16(0904-1850):5-40.

15. Chest ABYG. BPJ. Diaphragmatic motion studied by m-mode ultrasonography: methods, reproducibility, and normal values. Chest. 2009;135(2):391-400.

16. M I MS, medicine HTKSTS. HIJR. Effects of inspiratory muscle thixotropy on the 6-min walk distance in COPD. Respiratory medicine. 2008;102(7):970-7. 
17. Kp MK, Louise RNL, C A. PJ, R AP, F T-SL. Respiratory muscle training increases respiratory muscle strength and reduces respiratory complications after stroke: a systematic review. Journal of physiotherapy. 2016;62(3):138-44.

18. Pao-Tsai C, Chia-Ling C, Chin-Man W, Chia-Ying C. Effect of neuromuscular electrical stimulation on cough capacity and pulmonary function in patients with acute cervical cord injury. J Rehabil Med. 2006;38(1):32-6.

19. Singh Sally J, Puhan Milo A, Andrianopoulos Vasileios, Hernandes Nidia AMKE, Hill Catherine JLAL, Camillo Carlos Augusto TT, et al. An official systematic review of the European Respiratory Society/American Thoracic Society: measurement properties of field walking tests in chronic respiratory disease. Eur Respir J. 2014;44(6):1447-78.

20. Maddocks M, Nolan CM, Man WD-C, Polkey MI, Hart N, Gao W, et al. Neuromuscular electrical stimulation to improve exercise capacity in patients with severe COPD: a randomised double-blind, placebo-controlled trial. The Lancet Respiratory Medicine. 2016;4(1):27-36.

21. W X, K RLLG. W, Y H, L X, et al. Combination of inspiratory and expiratory muscle training in same respiratory cycle versus different cycles in COPD patients: a randomized trial. Respiratory research. 2018;19(1):225.

22. Illi SK, Held U, Frank I, Spengler CM. Effect of Respiratory Muscle Training on Exercise Performance in Healthy Individuals A Systematic Review and Meta-Analysis. Sports Med. 2012;42(8):707-24.

23. N V, R F, YJ C. A DT. Abdominal muscle use during breathing in patients wih chronic airflow obstruction. Am Rev Respir Dis. 1992;146(1):16-21.

24. Santiago G, Andrew D, Ellen PM, William D. M, A RR. Neuromuscular electrical stimulation prevents muscle function deterioration in exacerbated COPD: a pilot study. Respiratory medicine. 2012;106(10):1429-34.

25. Vivodtzev I, Pépin J-L, Vottero G, Mayer V, Porsin B, Lévy P, et al. Improvement in quadriceps strength and dyspnea in daily tasks after 1 month of electrical stimulation in severely deconditioned and malnourished COPD. Chest. 2006;129(6):1540-48.

26. Weiner P, Magadle R, Beckerman M, Weiner M, Berar-Yanay N. Comparison of Specific Expiratory, Inspiratory, and Combined Muscle Training Programs in COPD. Chest. 2003;124(4):1357-64.

27. F NL, H RM MPRD, C LMD, Graciele CC. S. Expiratory and expiratory plus inspiratory muscle training improves respiratory muscle strength in subjects with COPD: systematic review. Respiratory care. 2014;59(9):1381-88.

28. Jirakrit L, Decha P, Rungthip P, Jakkrit K. Effects of a simple prototype respiratory muscle trainer on respiratory muscle strength, quality of life and dyspnea, and oxidative stress in COPD patients: a preliminary study. Int J Chronic Obstr Pulm Dis. 2017;12:1415-25.

29. FE GPYCTB, A RQ G, J Q, et al. Functional Electrical Stimulation Changes Muscle Oxygenation in Patients with Chronic Obstructive Pulmonary Disease During Moderate-Intensity Exercise: A Secondary Analysis. COPD: Journal of Chronic Obstructive Pulmonary Disease. 2019;16(1):30-36.

30. McCaughey EJ, Jonkman AH, Boswell-Ruys CL, McBain RA, Bye EA, Hudson AL, et al. Abdominal functional electrical stimulation to assist ventilator weaning in critical illness: a double-blinded, randomised, sham-controlled pilot study. Crit Care. 2019;23(1):1-11.

31. Benjamin W, Henrik ASM, Dinesh WSAP, Miriam S. G, et al. Physical activity monitoring in COPD: compliance and associations with clinical characteristics in a multicenter study. Respiratory medicine. 2012;106(4):522-30.

\section{Figures}




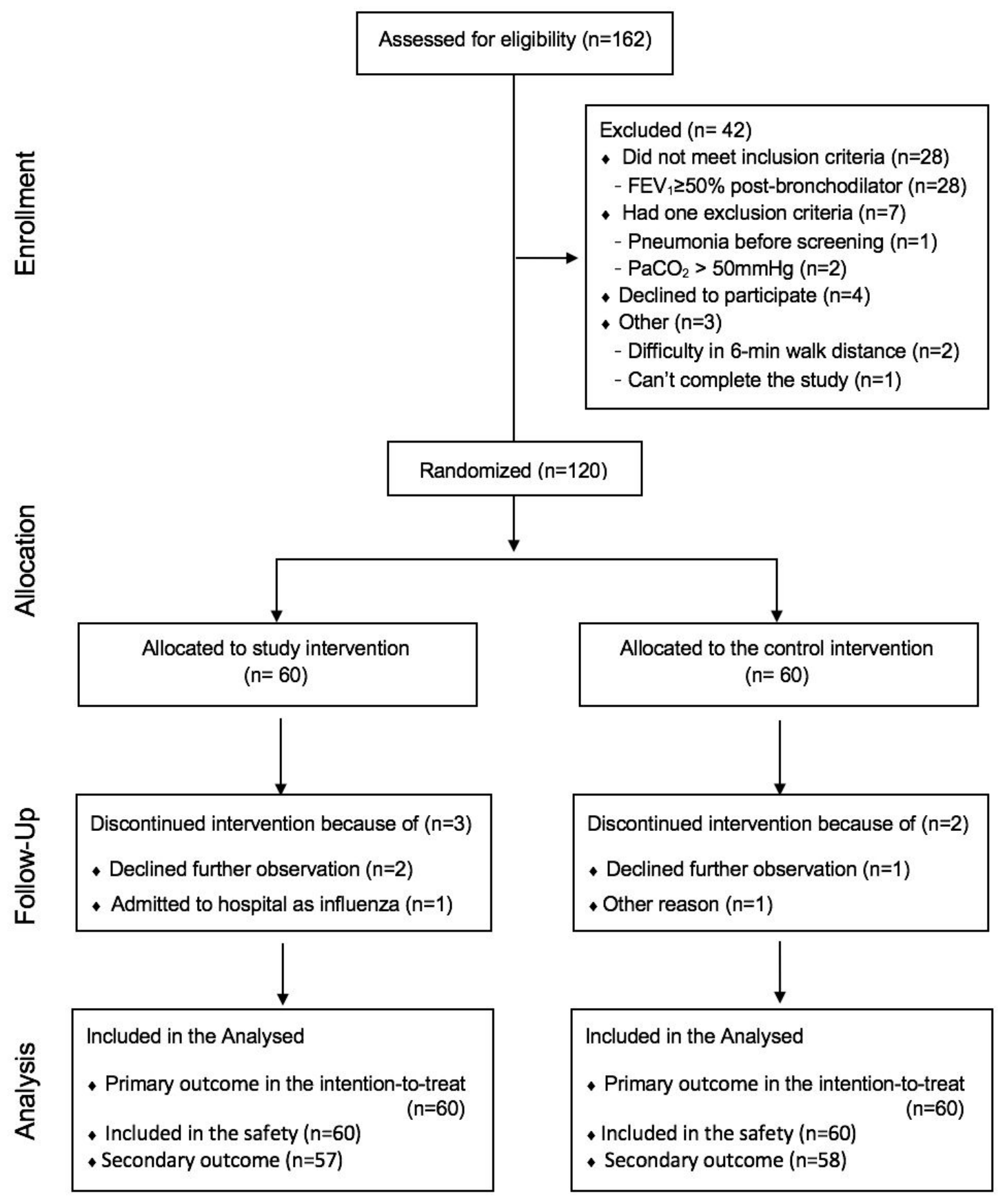

Figure 1

CONSORT diagram for study flow. Flow diagram illustrating the number of participants in each group. 

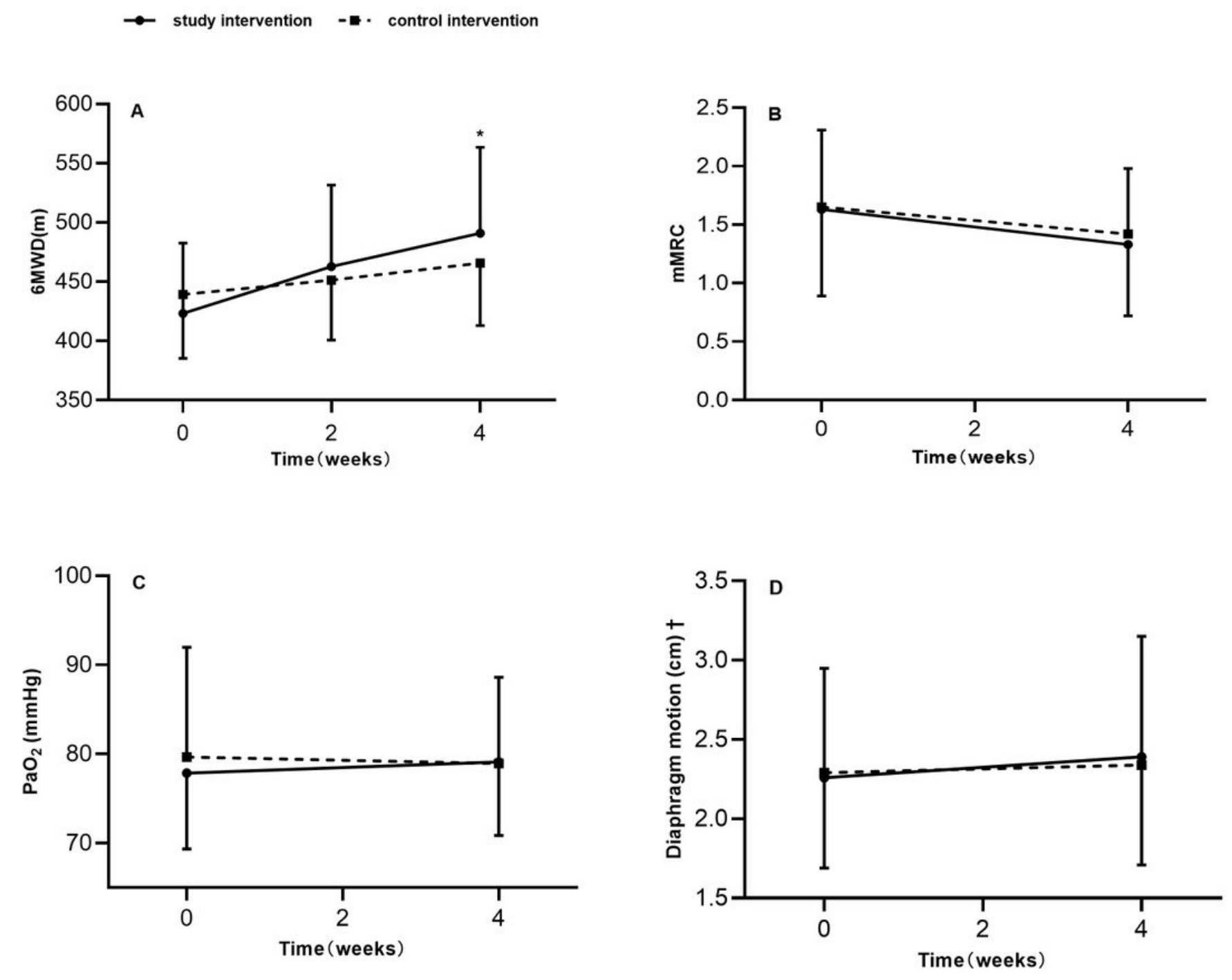

Figure 2

Changes of functional exercise capacity and secondary outcomes after two and four-week electrical stimulation betweengroup. (Figure 2A showed functional exercise capacity; Figure 2B showed the differences of mMRC, Figure 2C showed the changes of $\mathrm{PaO} 2$, and Figure 2D showed diaphragm motion after two and four-week electrical stimulation) * denote a significant between group difference of $\nabla<0.05$ at the end of four weeks. + Changes of diaphragm motion in quiet breathing between groups 

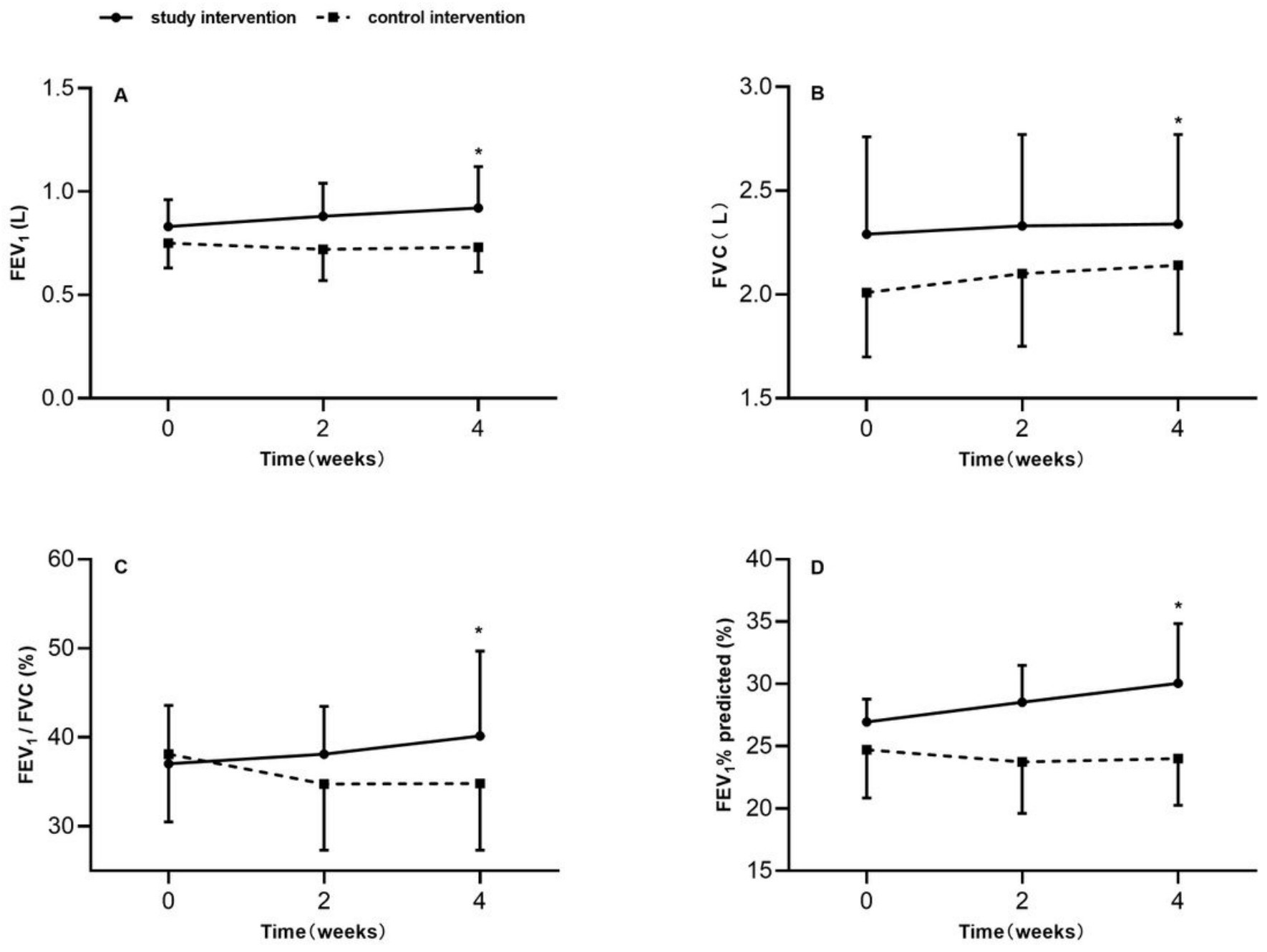

Figure 3

Pulmonary function changes in GOLD 4 group following two and four-week electrical stimulation. Figure 3A, Figure 3B, Figure 3C and Figure 3D showed FEV1,FVC, FEV1/FVC , and FEV1\%predicted retrospectively. * denote a significant between group difference of $\nabla<0.05$ at the end of four weeks. Abbreviations: FEV1 = forced expiratory volume in 1 second; FVC = forced vital capacity.

\section{Supplementary Files}

This is a list of supplementary files associated with this preprint. Click to download.

- OnlineDataSupplement6.19.docx 